\title{
Analysis Optimization of Results Distribution Function in Sprint Swimming Among Women
}

\author{
Gonsales S.E. \\ Physical upbringing and sport department \\ Russian University of Peoples' Friendship (RUPF) \\ Moscow, Russia \\ vniifk@yandex.ru
}

\begin{abstract}
The article analizes the function of sports results distribution at sprint swimming distances among women in competitions of two World Championships. The article defines the expediency of linearity and non-linearity ranges revelation of results distribution function according to ranks method. This method helped to differentiate groups of athletes, who had differences according to quantitative (composition of general group in each specialization of swimming) and qualitative (the level of special physical readiness) characteristics.

Results distribution function estimation was realized according to the values of angular and linear coefficients. These values characterized the density of competitions results distribution in the definite ranges (linearity/non-linearity) of distribution and in the definite degree, are associated with the level of special physical readiness. Linear coefficient corresponded with close-in prediction of sports result. We revealed clear differences of both coefficients values in the groups of each specialization of swimming. The received results underlined possible association of these parameters with the quality of competitiveness in competitions. Thus, a complex approach to results distribution function study in female sprint swimming provides an optimal quality of results analysis in speed swimming, forms relatively precise close-in prediction of sports result.
\end{abstract}

Keywords - sports result; sampling; group of female athletes; speed swimming; method of optimization; distribution function; linearity/non-linearity of distribution.

\section{INTRODUCTION}

Contemporary world sport development in general is characterized by the increasing scale and variety of competitive activity. Sports swimming is not an exception. At the international competitions there are not many participants in sprint swimming, which is connected with maximum tension of athletes' muscular activity $[1,2]$.

Within recent 2-3 years the approaches to scientific way of solutions revelation constantly change. These solutions are connected with the aspects of methodology of training athletes for important competitions [3,4,5]. Especially demanded are biomechanical study of speed swimming reserves [6,7] and also the questions of results analysis in professional sport $[8,9,10,11,12]$.
The urgency of this research work is conditioned by increased interest of specialists and athletes in progressive tendencies and technologies of sports development.

The aim of the research is a complex provision of the approach to results analysis optimization among the strongest women-athletes in sports swimming.

\section{RESEARCH METHODOlOGY}

Results distribution in swimming during the competitions at two World Championships (Kazan, Russia, 2015; Budapest, Hungary, 2017) were studied on the basis of the average speed of distance overcoming criterion during professional competitions.

The first objective solution is analysis optimization of results distribution function among female athletes. This objective provided criteria systematization and system format of the initial data determination. The female athletes' results presentation in accordance with the taken places defined the format of the average speed values rank distribution at the distance $\left(V_{\mathrm{av}}\right)$ for each way of swimming.

In individual average speed values distribution in general groups of female athletes, regardless of the way of swimming, there was participants alternation of linear and non-linear results distribution. For the participants of linear distribution it was typical to have minimal results differences, which can prove high level of competitiveness (special readiness) of the leading female athletes.

Enumerated variants and peculiarities of distribution of sports results can be presented in a format of linear function, however, more difficult in the formats of exponential polynomials (for example, the $2^{\text {nd }}$ or the $3^{\text {rd }}$ degrees). Methods of non-linear dependencies approximation were widely used earlier in the research works of the same type. At the same time, the leading role in results analysis optimization criteria formation belongs to the key parameters of a linear distribution - quantity (n) and the peculiarities of the studied samplings, angular coefficient $(a)$, linear coefficient $(b)$ and determination coefficient $\left(R^{2}\right)$.

In our research work we use linear variant of sports results distribution analysis. In order to increase the effectiveness of 
female athletes according to the ways of swimming. The

results regulation function analysis among sprint specialization female athletes, it is reasonable to present from the positions of variety general sampling of athletes in each discipline of swimming.

The second objective solution - the composition of female athletes optimization in each general group according to the way of sprint swimming - provided differentiated approach use to quantitative athletes ratio determination in different categories, from the position of the most trained female athletes status ("leaders" group), their closest competitors ("main" group) and the athletes, who finish the lists of protocols ("outsiders" group).

During the groups identification their typical characteristics were taken into consideration. Firstly, nonlinear character of values distribution of the average speed at the distance among the female athletes from "leaders" group, as a rule, is conditioned by distinct advantage of small amount of the most trained female athletes. Secondly, the specificity of "main" group, regardless of the way of swimming, was considered in the context of constant competition for "leaders" group. The number of athletes, who took part in the competitions in "leaders" and "main" groups, totally was no less than $50-60 \%$ from general number of participants in different ways of swimming. That is why "main" group division into two subgroups (A and B) in general case is not obligatory, but is reasonable in great samplings. Thirdly, considerable decrease of the average speed at the distance, regardless of the way of swimming, objectively showed insufficient level of special readiness of weaker female athletes ("outsiders" group).

Thus, the research defines two main methods of results analysis optimization in female specialization of speed swimming. Firstly, the method of characteristics revelation of sports results distribution $\left(V_{\mathrm{av}}\right)$ in general and specific groups of athletes for each way of swimming. Secondly, the differentiated method of quantitative compound determination of general samplings among female athletes according to each specialization of speed swimming.

\section{RESULTS}

Table 1 presents the main parameters of women's results distribution at sprint distance of 50 meters in different ways of swimming. There is one regularity in this case- in all ways of speed swimming the representatives of the main A group had relatively best average values of the angular coefficient $a$. This coefficient value varied within the following range: from 0.0023 till -0.0027 , in breaststroke and in free style. The range of angular coefficient $a$ variation in this group within the limits of the lower bound was from -0.0031 till -0.0046 , in swimming on the back and breaststroke swimming.

The presented results prove higher density of results among female athletes of A group $(p<0.001)$. At the same time, "retarded" values of the angular coefficient in any way of swimming could be conditioned by the influence of not completely favorable start fulfillment.

There was one more regularity in values of linear coefficient $b$ change in the groups of general sampling of values of this coefficient are close to the prediction- rated average speed at the distance of the nominal leader $\left(V_{\mathrm{av}} 1\right)$.

TABLE 1. THE MAIN PARAMETERS OF RESULTS DISTRIBUTION AMONG WOMEN AT 50 METERS DISTANCE IN DIFFERENT WAYS OF SWIMMING

\begin{tabular}{|c|c|c|c|c|c|}
\hline \multirow{2}{*}{$\begin{array}{l}\text { Specializat } \\
\text { ion of } \\
\text { swimming }\end{array}$} & \multirow{2}{*}{$\begin{array}{c}\text { Paramet } \\
\text { ers }\end{array}$} & \multicolumn{4}{|c|}{$\begin{array}{l}\text { Parameters of results approximation in the } \\
\text { groups of female athletes }\end{array}$} \\
\hline & & leaders & main $A$ & main $B$ & general \\
\hline 1 & 2 & 3 & 4 & 5 & 6 \\
\hline \multirow[t]{8}{*}{ Free style } & \multirow{2}{*}{$n$} & $16^{*}$ & 37 & 45 & 112 \\
\hline & & $16 * *$ & 26 & 39 & 87 \\
\hline & \multirow{2}{*}{$a$} & $0 . \overline{-}$ & -0.0027 & -0.0058 & -0.0063 \\
\hline & & $0 . \overline{-}$ & -0.0036 & -0.0087 & -0.0073 \\
\hline & \multirow{2}{*}{$b$} & 2.0773 & 1.9917 & 1.8854 & 2.1537 \\
\hline & & 2.0959 & 1.9986 & 1.9065 & 2.1514 \\
\hline & \multirow{2}{*}{$R^{2}$} & 0.9851 & 0.9926 & 0.9719 & 0.8094 \\
\hline & & 0.8257 & 0.9700 & 0.9760 & 0.8982 \\
\hline \multirow{8}{*}{$\begin{array}{l}\text { Butterfly } \\
\text { swimming } \\
\text { stroke }\end{array}$} & \multirow{2}{*}{$n$} & 15 & 20 & 20 & 64 \\
\hline & & 16 & 20 & 13 & 57 \\
\hline & \multirow{2}{*}{$a$} & $0 . \overline{-}$ & -0.0024 & -0.0092 & -0.0078 \\
\hline & & $0 . \overline{-}$ & -0.0038 & -0.0160 & -0.0087 \\
\hline & \multirow{2}{*}{$b$} & 1.9866 & 1.8878 & 1.8253 & 2.0365 \\
\hline & & 1.9888 & 1.8997 & 1.8309 & 2.0549 \\
\hline & \multirow{2}{*}{$R^{2}$} & 0.9088 & 0.9207 & 0.9599 & 0.8288 \\
\hline & & 0.6813 & 0.9689 & 0.9372 & 0.8898 \\
\hline \multirow[t]{8}{*}{ Back crawl } & \multirow{2}{*}{$n$} & 13 & 16 & 13 & 52 \\
\hline & & 16 & 25 & 16 & 62 \\
\hline & \multirow{2}{*}{$a$} & $0 . \overline{-}$ & -0.0027 & -0.0082 & -0.0081 \\
\hline & & $0 . \overline{-}$ & -0.0031 & -0.0076 & -0.0060 \\
\hline & \multirow{2}{*}{$b$} & 1.8368 & 1.7642 & 1.7250 & 1.8921 \\
\hline & & 1.8476 & 1.7771 & 1.6748 & 1.8846 \\
\hline & \multirow{2}{*}{$R^{2}$} & 0.9065 & 0.9396 & 0.9523 & 0.7662 \\
\hline & & 0.9669 & 0.9434 & 0.9605 & 0.8544 \\
\hline \multirow{8}{*}{$\begin{array}{c}\text { Breaststrok } \\
\text { e }\end{array}$} & \multirow{2}{*}{$n$} & 15 & 28 & 19 & 73 \\
\hline & & 16 & 16 & 14 & 51 \\
\hline & \multirow{2}{*}{$a$} & $0 . \overline{-}$ & -0.0023 & -0.0121 & -0.0076 \\
\hline & & $0 . \overline{-}$ & -0.0046 & -0.0162 & -0.0098 \\
\hline & \multirow{2}{*}{$b$} & 1.6736 & 1.6058 & 1.5522 & 1.7581 \\
\hline & & 1.6869 & 1.6079 & 1.5197 & 1.7580 \\
\hline & \multirow{2}{*}{$R^{2}$} & 0.8812 & 0.9837 & 0.9693 & 0.7642 \\
\hline & & 0.8976 & 0.9480 & 0.9858 & 0.8364 \\
\hline
\end{tabular}


The received results show that the values of $b$ coefficient decreases in accordance with relatively average level of female athletes' special physical readiness. In the "quickest" free style of swimming lagging of athletes from the main A group from the group of leaders according to the value of the linear coefficient varied within the range $4.12-4.64 \%$; in "the slowest" breaststroke - within the range $4.05-4.68 \%$. Lagging of female athletes from the main B group from the main A group according to the value of linear coefficient was

$4.60-5.34 \%$ in free style, and till $5.49 \%$ - in breaststroke.

At 100 meters distance of swimming by different ways the following results were received (table 2).

TABLE 2. THE MAIN PARAMETERS OF RESULTS DISTRIBUTION AMONG WOMEN AT 100 METERS DISTANCE IN DIFFERENT WAYS

\begin{tabular}{|c|c|c|c|c|c|}
\hline \multicolumn{6}{|c|}{ OF SWIMMING } \\
\hline \multirow{2}{*}{$\begin{array}{l}\text { Specializati } \\
\text { on of } \\
\text { swimming }\end{array}$} & \multirow{2}{*}{$\begin{array}{l}\text { Param } \\
\text { eters }\end{array}$} & \multicolumn{4}{|c|}{$\begin{array}{l}\text { Parameters of results approximation in the } \\
\text { groups of female athletes }\end{array}$} \\
\hline & & Leaders & $\operatorname{main} A$ & main $B$ & general \\
\hline 1 & 2 & 3 & 4 & 5 & 6 \\
\hline \multirow[t]{8}{*}{ Free style } & \multirow{2}{*}{$n$} & $16^{* * *}$ & 63 & -- & 89 \\
\hline & & 15 & 25 & 32 & 78 \\
\hline & \multirow{2}{*}{$a$} & -0.0047 & -0.0034 & --- & -0.0041 \\
\hline & & -0.0049 & -0.0038 & -0.0062 & -0.0058 \\
\hline & \multirow{2}{*}{$b$} & 1.8995 & 1.8441 & --- & 1.9170 \\
\hline & & 1.9166 & 1.8402 & 1.7535 & 1.9485 \\
\hline & \multirow{2}{*}{$R^{2}$} & 0.9226 & 0.9799 & --- & 0.8853 \\
\hline & & 0.9639 & 0.9875 & 0.9039 & 0.8774 \\
\hline \multirow{8}{*}{$\begin{array}{l}\text { Butterfly } \\
\text { swimming } \\
\text { stroke }\end{array}$} & \multirow{2}{*}{$n$} & 17 & 24 & 22 & 69 \\
\hline & & 23 & 17 & --- & 46 \\
\hline & \multirow{2}{*}{$a$} & -0.0035 & -0.0033 & -0.0072 & -0.0055 \\
\hline & & -0.0043 & -0.0084 & --- & -0.0077 \\
\hline & \multirow{2}{*}{$b$} & 1.7617 & 1.7162 & 1.6235 & 1.8102 \\
\hline & & 1.7806 & 1.6934 & --- & 1.8274 \\
\hline & \multirow{2}{*}{$R^{2}$} & 0.7013 & 0.9375 & 0.9460 & 0.8707 \\
\hline & & 0.9282 & 0.8694 & --- & 0.8296 \\
\hline \multirow[t]{8}{*}{ Back crawl } & \multirow{2}{*}{$n$} & 9 & 29 & 21 & 65 \\
\hline & & 12 & 23 & 16 & 59 \\
\hline & \multirow{2}{*}{$a$} & -0.0050 & -0.0022 & -0.0065 & -0.0048 \\
\hline & & -0.0049 & -0.0029 & -0.0089 & -0.0062 \\
\hline & \multirow{2}{*}{$b$} & 1.7172 & 1.6680 & 1.6027 & 1.7428 \\
\hline & & 1.7215 & 1.6621 & 1.6026 & 1.7598 \\
\hline & \multirow{2}{*}{$R^{2}$} & 0.9482 & 0.9913 & 0.9899 & 0.8319 \\
\hline & & 0.9282 & 0.9775 & 0.9882 & 0.8487 \\
\hline \multirow{4}{*}{$\begin{array}{l}\text { Breaststrok } \\
\quad \mathrm{e}\end{array}$} & \multirow{2}{*}{$n$} & 15 & 29 & 19 & 68 \\
\hline & & 16 & 18 & 14 & 53 \\
\hline & \multirow{2}{*}{$a$} & -0.0028 & -0.0032 & -0.0093 & -0.0049 \\
\hline & & -0.0048 & -0.0044 & -0.0102 & -0.0065 \\
\hline
\end{tabular}

\begin{tabular}{|c|c|c|c|c|c|}
\hline \multirow{2}{*}{$b$} & 1.5213 & 1.4923 & 1.3976 & 1.5668 \\
\cline { 3 - 6 } & & 1.5472 & 1.4921 & 1.3983 & 1.5841 \\
\cline { 2 - 6 }$R^{2}$ & 0.9174 & 0.9669 & 0.9877 & 0.8804 \\
\cline { 3 - 6 } & 0.7996 & 0.9633 & 0.9651 & 0.8949 \\
\hline \multicolumn{2}{|l}{ Notes -*** the same as in table. 1. }
\end{tabular}

The received results help to come to the following conclusion.

\section{CONCLUSIONS}

1. Analysis optimization of competitions results in swimming is conditioned by the ranges of non-linearity in the rank dynamics of sports results distribution. The format of rank values succession of the average speed of sprint distance overcoming, regardless of the way of swimming, is informative in studying the functions of athletes' results distribution.

2. The highest density of results in the competition characterizes the corresponding level of physical and technical readiness and is an integral index of high competitiveness in competitions.

3. The necessary part of analysis optimization of female athletes' results distribution function is the quantitative content of each group estimation ("leaders", "main A" group and "main B" group) in terms of specialization of swimming.

4. Additional test calculations showed that the results of studying the function of results distribution depend on random or deliberate parameters changes of the studied groups of female athletes according to each specialization. The differences in estimation can be $5-6 \%$, which is considerable difference in sprint swimming specialization.

We express our thanks to the heads, organizers and officials of the I International Povolzhskaya conference in economics, humanitarian sciences and sport "FICEHS 2019" September, 24-25, Kazan, Naberezhnye Chelny, Russia- for the opportunity to take part in this great event.

\section{References}

[1] A. Lavie "The swimming of the POD: Theoretical analysis and experimental results." IEEE Trans. on Magn. 1970, vol. 6, 2, pp. 365-367. doi: 10.1109/TMAG.1970.1066809.

[2] R. Schulz, and Ch. Curnow, "Peak Performance and Age Among Superathletes: Track and Field, Swimming, Baseball, Tennis, and Golf," Journal of Gerontology. 1988, vol. 43, 5 (September 1988), pp. 113-120. https://doi.org/10.1093/geronj/43.5.P113.

[3] A. J. Silva, A. Rouboa, A. Moreira, V. M. Reis, F. Alves, J. P. VilasBoas, and D. A. Marnho, "Analysis of Drafting Effects in Swimming using Computational Fluid Dynamics." Journal of Sports Science and Medicine. 2008, 7, pp. $60-66$.

[4] W. Weimar, A. Summer, B. Romer, J. Fox, J. Rehm, B. Decoux, and J. Patel, "Kinetic Analysis of Swimming Flip-Turn Push-Off Techniques." Journal Sports. 2019, vol. 7, 2, pp. 32. URL: https://doi.org/10.3390/sports7020032; https://www.mdpi.com/2075$4663 / 7 / 2 / 32 / \mathrm{htm}$

[5] A. B. Ramos-Hryb, Z. Bahor, S. McCann, E. Sena, M. R. MacLeod, and C. Lino de Oliveira, "Protocol for a Systematic Revew and Meta-analysis of Data from preclinical Studies Employng forced swimming test: an Update." BMJ Open Science (September,13, 2019). 2019, vol. 3, e000035. doi: 10.1136/bmjos-2017-000043. http://openscience.bmj.com/. 
[10] B. Radulovic, "The Analysis of trend of Swimming Results in Montenegro from 2000-2009." Sport Mont. (2010), Vol. VIII, 23-24, pp. 219-225. http://www.sportmont.ucg.ac.me/?sekcija=article\&artid=332; http://www.sportmont.ucg.ac.me/clanci/SportMont_Dec 2010 Radulovic 219-225.pdf. pp. 31-36.

[7] F. Krüger, "Analysis of kinematic parameters during competitive backstroke swimming." International Series on Sport Sciences book series (MMSS), Biomechanics IV (Palgrave, London, Print ISBN 978-1-34902614-2). pp. 208-216. doi: https://doi.org/10.1007/978-1-349-026128_30.

[8] B. R. Mason, J. Fowlie, "Competition Analysis for high Performance swimming." In Book: "The AIS International Swim Seminar Proceedings"; Chapter: Competition Analysis for High Performance Swimming, Publisher: Australian College of Sports Education, Editors: Australian Institute of Sport. 1997, pp. 5- 18 .

[9] M. Elipot, G. Dietrich, P. Hellard, and N. Houel, "CinAnalysis: A new Software for Swimming Races Analysis." 8 th Conference of the International Sports Engineering Association (ISEA) Poster Session II (July 2010), Abstracts: Procedia Engineering. 2010. pp. 3467. doi:10.1016/j.proeng.2010.04.191.

[11] C. Tomasz, R. Muszkieta, and M. Cieślicka, "Analysis of results European Swimming Championship in London." Journal of Education, Health and Sport. 2016, vol. 6, 10, pp. 754-771. doi: http://dx.doi.org/10.5281/zenodo.258831.

[12] T. Całka, R. Muszkieta, and M. Cleślicka, "Analysis of results European Swimming Championship in London 2016." Journal of Education, Health and Sport. 2016, vol. 6, 10, pp. 754-771. URL: http://doi.org/10.5281/zenodo.258831

[13] Evgeniya A. Raspopova, Irina V. Chebotareva. Physical development of young 11-13-years-old swimmers and divers. The Russian Journal of Physical Educationand Sport. 2019, 14(1), pp. 29-33. DOI: 10.14526/2070-4798-2019-14-1-33-37. 